\title{
Power system restoration: a literature review from 2006 to 2016
}

\author{
Yutian LIU ${ }^{1}$, Rui FAN ${ }^{1}$, Vladimir TERZIJA ${ }^{2}$
}

\begin{abstract}
Power system restoration has attracted more attention and made great progress recently. Research progress of the power system restoration from 2006 to 2016 is reviewed in this paper, including black-start, network reconfiguration and load restoration. Some emerging methods and key techniques are also discussed in the context of the integration of variable renewable energy and development of the smart grid. There is a long way to go to achieve automatic self-healing in bulk power systems because of its extreme complexity. However, rapidly developing artificial intelligence technology will eventually enable the step-by-step dynamic decision-making based on the situation awareness of supervisory control and data acquisition systems (SCADA) and wide area measurement systems (WAMS) in the near future.
\end{abstract}

Keywords Large-scale blackout, Power system restoration, Self-healing, Smart grid, Renewable energy, Wide area measurement system (WAMS), Cyber attack

CrossCheck date: 8 June 2016

Received: 26 March 2016/ Accepted: 8 June 2016/Published online: 19 July 2016

(C) The Author(s) 2016. This article is published with open access at Springerlink.com

$\triangle$ Yutian LIU

liuyt@sdu.edu.cn

Rui FAN

fanrui@mail.sdu.edu.cn

Vladimir TERZIJA

Vladimir.Terzija@manchester.ac.uk

1 Key Laboratory of Power System Intelligent Dispatch and Control of Ministry of Education, Shandong University, Jinan 250061, China

2 Department of Electrical and Electronic Engineering, University of Manchester, Manchester M13 9PL, UK

\section{Introduction}

The modern power system is pushed close to critical operating limits in the market environment. High capacity and long transmission networks are widely used to meet the power supply demand of modern society. Wind and solar power as clean and renewable energy are significantly adopted but they are inherently volatile, intermittent and random. Therefore, an improper handling of certain partial failures can easily lead to accidents and severe chain reactions, and thus may cause large-scale/extensive blackout eventually.

In recent years, there have been a great number of widespread blackouts around the world. For example, the North American blackout on August 14, 2003 caused a huge loss and the restoration of power supply lasted almost two weeks [1]. The European power outage on November 4, 2006 affected 15 million people and lasted up to 2 hours. Brazil and Paraguay experienced an extensive blackout on November 10, 2009. The Fukushima nuclear power plant was shut down in an emergency after the earthquake and tsunami on March 11, 2011, and its external power and emergency power were not adequate enough to support the cooling system and caused radiation leakage and other catastrophic consequences. The largest power outage in northern India involved $50 \mathrm{GW}$ of load, affected 670 million people and lasted from July 30-31, 2012 [2].

Large-scale blackout risks still exist and are inevitable, although a great amount of work has been done to make power systems resilient against outages [3]. A proper restoration plan can effectively mitigate the negative impact on the public, the economy, and the power system itself. Research on how to restore the power system quickly and effectively after outages is of vital significance. 
Power system restoration after a partial or complete collapse is quite a complex process. Many factors need to be considered including the operating status of the system, the equipment availability, the restoration time and the success rate of operation. It needs not only a large amount of analysis and verification, but also decisions made by dispatching personnel. Power system restoration is a multi-objective, multi-stage, multi-variable and multi-constraint optimization issue, and is full of non-linearity and uncertainty. It can be described as a typical semi-structured decision-making and it is difficult to obtain a complete solution [4].

The objectives of restoration are to enable the power system to return to normal conditions securely and rapidly, minimize losses and restoration time, and diminish adverse impacts on society. Many non-structured methods and technologies and object-oriented expert system have been employed in making restoration schemes to address the above objectives, but the establishment and maintenance of a knowledge base of past restorations remains a bottleneck. Case-based reasoning [5] is dependent on typical scenarios. With the development of computational intelligence, some heuristic algorithms such as genetic algorithms [6], artificial neutral networks [7] and fuzzy logic [8] are applied to system restoration, which may be a promising path forward. Graph theory with Petri nets [9] is also employed, but verification of constraints and reduction of uncertainties both need improvement. Based on the regional distribution characteristics in space, multi-agent technologies [10-13] are developed with potential prospect. As a functional extension of expert systems and heuristic rules, decision support systems [14] have been demonstrated efficiently.

A bibliographical survey of publications covering the 1980s and 1990s is provided in nine different topics by [15]. Power system restoration is still a very active and hot research area up to now. To analyze it effectively, the three stages of black-start, network reconfiguration and load restoration are considered. This paper presents a review of the last decade of research, covering the areas of blackstart, network reconfiguration, load restoration, and emerging technologies from the year of 2006, applying to transmission system restoration; distribution system restoration [16] is beyond this paper's focus.

\section{Black-start}

The black-start stage, also called preparation period, is a stage in which a black-start generator provides cranking power to restart a non-black-start (NBS) generator. Related research mainly includes black-start power source selection, scheme formulation and assessment, field testing, dynamic and protection issues, and sectionalization strategy for parallel restoration.

\subsection{Black-start power source selection}

Usually, black-start power sources include the units with self-start ability such as hydroelectric generating units, fuel and gas turbine units and support power provided by adjacent interconnected systems. Gas-turbine-based plants can be profitably used in power system restoration [17]. The black-start resource procurement decision can integrate with a restoration planning model using optimization to produce a minimal cost procurement plan [18].

\subsection{Scheme formulation and evaluation}

Black-start schemes are generally formulated according to effectiveness and reliability. General guidelines of the considerations and needs for the development of effective restoration plans are described in [19] for electric utilities serving large metropolitan areas. Ref. [20] proposes the concept of success rate of unit restoration. It selects the optimal restored unit in advance and restoration paths are obtained by the algorithm of $K$-shortest paths. To generate the most suitable black start schemes, knowledge-based expert systems with decision support techniques are utilized [14, 21]. In [21], an expert system is developed by combining a fast reasoning mechanism with object-oriented features considering time-varying load. Restoration plans developed offline are used as guidelines for dispatchers in an online environment. Ref. [14] discusses online decision support tools for system restoration. Ref. [22] develops a black-start decision-support system that serves as an offline planning tool with an interactive graphical user interface. A hybrid approach combining graph algorithm and swarm intelligence is adopted to achieve the optimal solutions. Ref. [23] analyzes the current automated black-start program of the ERCOT grid, and gives a new black-start service annual selection analysis by a method of islanded formation.

Evaluation methods are available to choose the best from the feasible solutions offered by black start schemes such as those above. A hierarchical process-based method using fuzzy analysis is proposed to assess black-start schemes [24]. Vague set theory is also introduced to make black-start scheme decisions in [25], which can reasonably deal with the correlation among the evaluation indices of the black-start schemes and fuzzy information in the blackstart decision. Ref. [26] presents an intuitive fuzzy distance-based method to analyze the consistency of blackstart group decision-making results. The weights of blackstart indices as well as the weights of decision-making experts are modified dynamically until a satisfactory result is obtained.

These black-start scheme generation and evaluation processes are generally carried out offline. Default 
scenarios used offline may be different from actual blackstart situations, so a black-start scheme may not play its role as expected.

\subsection{Field testing}

In order to improve the efficiency of restoration schemes, many power companies have conducted blackstart field tests. The Shandong power grid of China has performed a series of black-start field tests using Taishan pumped storage power station as cranking power, which makes full use of the long-term operation capability of pumped storage units in ultra-low load conditions, according to principles of risk management, continuous improvement, and accident priority control. Ref. [27] summarizes the main problems to be addressed during the field tests, and proposes a black-start field test management method based on the plan-do-check-action (PDCA) model to achieve standardized management of black-start field tests. Italy [17], Japan [28] and Sweden [29] have also reported their experiences of black-start tests in verifying the feasibility of black-start schemes. These field tests provide valuable advice to help system operators to improve their restoration schemes. It is necessary to do some field tests, alongside simulations, to improve the restoration efficiency.

\subsection{Dynamic and protection issues}

The frequency excursions are arrested automatically by various control and protection devices immediately after a major disturbance. However, it is challenging to coordinate the control and protective mechanisms with the operation of generating plants and the electrical system. During the subsequent restoration phases, plant operators in coordination with system operators attempt to manually maintain a real and reactive power balance. The duration of these manual procedures have invariably been much longer than equipment can endure. Several dynamic phenomena are presented and the required research and development identified in [30].

Ref. [31] updates the protection issues that occur during power system restoration. An effort has been made to cover most of the general protection related issues that can arise during power system restoration, and the functions that can be used to improve relay operation and also support the system operator in the restoration process.

\subsection{Sectionalization strategy}

To facilitate rapid power system restoration, the power system needs to be divided into several subsystems for parallel restoration. Ref. [32] employs a method based on an ordered binary decision diagram to derive proper splitting strategies for large-scale power systems. Ref. [33] presents a novel sectionalization method based on the wide area measurement system (WAMS) for the build-up strategy in power system restoration. In [34], a new method is proposed to divide systems for restoration based on the community structure of complex network theory. A modularity index is employed to evaluate the optimal number of the restoration subsystems. Ref. [35] proposes an optimization model for optimal sectionalization of restoration subsystems with a special emphasis on the coordination of generator ramping and the pickup of critical loads. A methodology based on constrained spectral clustering uses the physical and inherent properties of the network to determine a suitable sectionalization strategy in [36]. The dynamic restoration partition method adapts to deal with different scenarios after the blackout.

For some systems, inability to control the voltage and frequency may lead to unsuccessful restoration. Suitable islanding can help to improve the feasibility and reliability of restoration by simplifying complex restoration processes [37].

\section{Network reconfiguration}

In network reconfiguration phase, the generation capacity obtained after the black-start is used to restore other important units and substations in a reasonable startup sequence, establishing a stable backbone network and laying foundation for full load restoration. Due to its complex features, network reconfiguration needs to be carried out under the guidance of restoration strategies. A three-stage restoration strategy [38] is proposed to manage this process, i.e. start-up of main units, restoration of important substations, and restoration of regional interconnection. Related research focuses on the unit start-up sequence optimization, the backbone-network determination, the restoration path optimization, and the transmission loop paralleling.

\subsection{Unit start-up sequence optimization}

The start-up of main units is one of the core missions. A reasonable unit start-up sequence can effectively speed up the restoration process and shorten the outage time. Related research can be divided into two categories: decisionmaking methods, and multi-optimization methods.

A decision-making technology is developed to determine the start-up sequence according to some established rules or policies in [39]. A series of restoration strategies are applied for optimizing the unit start-up sequence for the purpose of maximizing restored generation capacity 
according to the start-up power, starting time, ramping rate and critical maximum time interval of generating units.

A large number of studies consider the unit start-up sequence as an optimization problem and employ nonlinear programming or artificial intelligence methods to solve it. Ref. [40] formulates the starting sequence of generators as a mixed integer linear programming problem, using the transformation technique on the nonlinear generation capability curves. However, it is not suitable for large-scale power systems due to the computational limitations of this method. In [41], unit start-up is treated as a two-layer restoration process, namely network-layer unit restarting and plant-layer unit restarting. The lexicographic optimization method is used to solve the resulting multi-objective optimization problem. Ref. [6] proposes a multi-objective optimization model for the unit start-up sequence, system-partitioning strategy and time requirements. NSGA-II is applied to find Pareto solutions and the Dijkstra algorithm is utilized to search for the restoration paths in the identified unit restoration sequence.

To reduce the optimization scale in above mentioned research, a two-phase method is usually employed with a lower solution quality. Ref. [42] establishes a multi-objective optimization model of unit restoration with primary and secondary relations in optimization goals, simultaneously taking the optimization of unit restoration sequence and the target network into account in the network reconfiguration phase.

\subsection{Backbone-network determination}

In most current studies, evaluation indices of the target network are set up in terms of topological structure or electrical parameters. A network reconfiguration objective function is established, and a suitable optimization algorithm is selected to solve the problem. In [43], the method of node contraction is introduced to assess the importance of nodes. The network reconfiguration efficiency is defined as the optimization objective and a discrete particle swarm is employed to obtain the optimal skeleton networks. In [44], the discrete particle swarm is used to determine backbone network with the objective that important load restoration accounts for the maximum percentage of the total load restoration. However, the above studies do not consider the constraints of the unit start-up time. In [45], a fuzzy chance constrained model is proposed to cope with the uncertainty of operating time and lines put into operation. A combined method of fuzzy simulation, crossing particle swam optimization (PSO) with the Dijkstra algorithm, is used to solve this model.

Multi-attribute decision-making methods are also used to solve this problem with positive outcomes. Ref. [46] proposes a dynamic optimization decision-making method for power system skeleton restoration. It employs a three-stage skeleton restoration strategy and a shortest path searching method to generate candidate schemes for each restoration step. The main factors influencing the power system security or restoration speed are chosen as the attributes of candidate schemes and a multi-attribute decision-making method is used to make the optimal decision. Ref. [47] presents a group decision support system which combines multiple attribute decision-making and group decision-making to aggregate different attributes and multiple experts' opinions to make decision-making more reasonable. In order to evaluate candidate restoration schemes, multiple types of attributes including crisp data, fuzzy numbers, interval numbers and linguistic terms are employed in [48]. A hybrid multiple attribute decision-making method based on VIKOR is proposed to provide compromise solutions.

\subsection{Restoration path optimization}

The establishment of the backbone-network has to be carried out step by step and the restoration path optimization in each step needs to minimize the cost of the target network formation while considering constraints. Each study has a unique feature in this area. In [49] the data envelopment analysis method incorporating preference information is employed to implement the modeling and evaluation of the weight coefficient with respect to each transmission line. Considering the failure risk of restoring transmission lines, two robust optimization models are presented in [50] to minimize total line restoration risk, which are applied to the series and parallel restoration stages, respectively. Ref. [51] proposes a network reconfiguration method based on the weighted complex network model. It can simultaneously obtain the globally optimal sequence of restoration paths and the optimal skeletonnetwork. Ref. [52] proposes a hierarchical collaborative optimization method according to the characteristics of hierarchical scheduling in power system. The objectives are defined as network reconfiguration degree and total power production. It combines hierarchical optimization with overall searching of the feed point index value which considerably reduces the scale of the problem. In [53], two types of restoration performance indices are used to rank all possible restoration paths according to their expected performance characteristics. The power transfer distribution factors and weighting factors are used to determine the order of restoration paths, which can enable the load to be picked up by lightly loaded lines or to relieve stress on heavily loaded lines. 


\subsection{Transmission loop paralleling}

When two or more sectionalized subsystems are restored to a certain extent, a parallel operation is needed to interconnect them. The standing phase angle (SPA) difference is critical to improve the success rate of the parallel operation. Ref. [54] models the SPA reduction problem as a mixed discrete-continuous optimization with various constraints. The objective function is to minimize the weighted sum of the active power generation adjustments and load shedding, which is solved by a genetic algorithm. Ref. [55] proposes an optimal control strategy for SPA reduction. Load pickup is combined with active power generation increment according to a control strategy developed with an alternative two-stage decoupled algorithm and mixed integer nonlinear programming. It is an additional advantage that more load restoration in the regulating process can meet the parallel conditions.

\section{Load restorations}

The fundamental purpose of restoration is to resume the power supply to the users or loads. Both in black-start and network reconfiguration phases, it is necessary to restore certain loads for balancing the unit output, maintaining the power balance and voltages within an acceptable range, and these are called ballast loads. Large-scale load restoration can be carried out when the backbone network is restored and main generators are connected to the network. It is very important to restore all the loads as fast as possible.

\subsection{Load restoration time}

The restoration time is the most important variable in load restoration problem, because penalty regimes for network operators are usually based on the length and capacity of load interruption. The methodology in [56] graphically visualizes power system restoration plans to help evaluate the restoration duration and the scheduled critical path, as part of a method of evaluation and review. Ref. [57] proposes a new method to estimate the recovery time based on machine learning methods applied to previous restoration events.

\subsection{Load restoration amount}

In general, load restoration is composed of multi-step load pickups. Single-step load restoration in a substation usually aims to activate one or more circuits at the same time. If the single pick-up is too heavy, it will lead to lower voltage and even frequency excursion. On the other hand, if the load pick-up is too light it will increase the number of operations and delay the restoration process. To evaluate load restoration amount, the cold load pick-up (CLPU) characteristics should be considered [58]. Ref. [59] uses linearization techniques to construct a generic model for a fast assessment of the dynamic characteristics of system frequency during the period of cold load pickup. The PSO algorithm is applied to determine the optimal load restoration amounts and locations in the case of cold load pickup [60]. Ref. [61] deals with discrete load restoration based the real-time system status measured by the WAMS.

It is necessary not only to keep steady-state constraints, but also to maintain transient constraints during the load restoration process. Ref. [62] proposes a comprehensive model for calculating the maximum restorable load amount within the constraints. It considers transient frequency constraints, transient voltage-dip constraints, steady-state voltage constraints, and CLPU characteristics using a modified bisection algorithm.

Ref. [63] analyzes the main considerations of load restoration in the unit start-up stage, and of restoration strategies in coordination with unit start-up. Regarding load restoration in the last stage of network reconfiguration, Ref. [64] presents a combinatorial optimization model to address the sequencing problem of load pickup.

\section{Emerging technologies}

With the integration of variable renewable energy [65] and development of the smart grid, emerging technologies are causing widespread impact. Although there are many new challenges [66, 67], some new opportunities exist to restore power systems quickly.

\subsection{Microgrid}

The emergence of microgrids embedded in power systems enhances self-healing capability and allows distribution systems to recover faster in the event of an outage. A microgrid can operate in an islanded mode in isolation from the connected system during an outage. In [68], a graph-theoretic restoration strategy is presented incorporating microgrids that maximizes the restored load and minimizes the number of switching operations. Spanning tree search algorithms are applied to find the candidate restoration strategies by modeling microgrids as virtual feeders. A simultaneous bidirectional approach in [69] deals with black-start restoration sequences. The control strategies to be adopted for microgrid black-start and subsequent islanded operation, as well as the appropriate rules and conditions, are derived and evaluated by 
numerical simulations. Ref. [70] deals with the multi-stage restoration scheduling problem in an islanded microgrid system with multiple distributed generators and a radial configuration. Two stochastic methods are used to solve it. Under appropriate conditions, distributed generation (DG) can maintain power supply for loads in microgrid after blackout, and can give some power support for adjacent microgrids, or even the main grid if properly synchronized [71].

Recent development in wind farm control has enhanced the integration of wind power into power system. However, the risk of power system blackouts is also increased due to the volatility and uncertain nature of wind power generation. There has not been much research on the potential restoration function of wind farms in power systems. Since the starting time of wind turbines is shorter than non-blackstart (NBS) generating units, some wind farms have the potential to function as black-start power sources in certain circumstances. The firefly optimization algorithm is used in [72] to find the optimal final sequence of NBS unit restoration, the optimal transmission path, and the optimal load pick up sequence with and without integration of wind farms in the system. Ref. [73] introduces a hybrid blackstart unit containing combustion gas turbine, wind farm and static synchronous compensator and a three-level control model to achieve comprehensive functionality. A control scheme can allow variable speed wind turbines to participate effectively in system frequency and voltage regulation as Ref. [73] describes. When wind farms with adequate energy storage can be guided by suitable control strategy, they will be a great help to power system restoration.

\subsection{VSC based HVDC}

High voltage direct current (HVDC) transmission lines using voltage-source converter (VSC) have superior performance and characteristics compared to traditional line commutated converter (LCC) technology, and can become a reliable external power supply for supporting black-start [74]. The study presents the possibility that HVDC links can use a synchronous compensator at the receiving end [75]. Such systems have high regulating capacity and reliability which are valuable characteristics during the critical phases of power system restoration. A detailed stability analysis is developed for checking the correct size of the compensator. Electromagnetic simulations prove the validity of the solution. The VSC based HVDC will be of potential neighbor power support for power system restoration.

\subsection{WAMS and cyber-attack}

WAMS provides more timely and accurate data to power system operators. In [33], a novel sectionalizing method is proposed for the build-up strategy including two processes, restoring separated parts (islands) in the power system and then interconnecting them afterwards. Each island ensures observability and provides the phase angle difference between adjacent stations using the WAMS. In [61], a restorable load estimation method is proposed employing WAMS data after the network frame has been reenergized, and the WAMS is also employed to monitor the system parameters in case the newly recovered system becomes unstable again. Ref. [76] presents a method for optimal restoration planning which uses observability analysis and power transfer distribution factor (PTDF) to decrease the overvoltages caused by energizing transmission lines with light load. The use of the WAMS at the early stages of restoration provides precise determination of generators loading steps. It is a significant benefit of WAMS to unify phase angle references at different islands and present a tie line energizing priority list at the last stages of restoration [77]. Ref. [78] explores a methodology to control and monitor frequency during the early steps of power system restoration, and uses generator modeling to calculate the single machine equivalent of the power system based on phasor measurement unit (PMU) measurements. There is potentially highly valuable opportunity to take full advantage of WAMS's timely situation awareness in rapid and effective power system restoration.

Ukraine suffered a serious cyber-attack on December 23, 2015, leaving hundreds of thousands of homes in the dark in what security experts say was a first for hackers with ill intent. A security firm claimed that it obtained malicious code to execute a temporary takedown of three power substations on the Ukrainian national grid [79]. The outage left about half of the homes in the Ivano-Frankivsk region of Ukraine without electricity. This is the first known instance of a blackout being credibly linked to the actions of malicious hackers. Cyber-attack is different from conventional faults and physical attack. It uses vulnerabilities of information domain to disturb the normal work of the monitoring system or communication network. Cyber-attack can trigger a blackout due to the dependence of the power system on information infrastructure. Power system restoration also relies on the information system, especially SCADA, to acquire the system status and thus to develop the restoration plan. Therefore, cyber-attack can delay or mislead the system restoration process. Cyberattacks have a long incubation period and low cost, and present a significant risk to power systems and the power industry. The Israel Electric Authority, not the power grid, has also been subjected to a cyber-attack, though this was misinterpreted by the media as a power system attack [80]. It is crucial to get prepared to defend power systems against such attacks. 
Table 1 Statistical result of reviewed publications

\begin{tabular}{|c|c|c|c|c|}
\hline Year & Black-start & Network configuration & Load restoration & Emerging Technology \\
\hline 2006 & $\begin{array}{l}\text { [19] Metropolitan service } \\
\text { issue }\end{array}$ & [12] Multi-agent & [58] Cold load pickup & \\
\hline 2007 & [5] Case based reasoning & $\begin{array}{l}\text { [43] Topological } \\
\text { characteristics } \\
\text { [44] Load importance }\end{array}$ & $\begin{array}{l}\text { [56] Graph visualization } \\
\text { [60] Cold load pickup }\end{array}$ & $\begin{array}{l}\text { [69] Simultaneous bidirectional } \\
\text { approach }\end{array}$ \\
\hline 2008 & $\begin{array}{l}\text { [17] Gas turbine } \\
\text { [21] Expert system } \\
\text { [28] Voltage building-up } \\
\text { [30] Dynamics issue } \\
\text { [37] Voltage and frequency }\end{array}$ & & & \\
\hline 2009 & [23] Ancillary services & $\begin{array}{l}\text { [6] NSGA-II } \\
\text { [38] Group decision-making } \\
\text { [51] Weighted complex } \\
\text { network }\end{array}$ & & $\begin{array}{l}\text { [67] Knapsack problem graph } \\
\text { modeling } \\
\text { [75] Receiving end synchronous } \\
\text { compensator }\end{array}$ \\
\hline 2010 & $\begin{array}{l}\text { [24] Fuzzy sets } \\
\text { [27] PDCA cycle }\end{array}$ & $\begin{array}{l}\text { [53] Power transfer } \\
\text { distribution factors } \\
\text { [54] GA }\end{array}$ & & \\
\hline 2011 & $\begin{array}{l}\text { [10] Multi-agent } \\
\text { [29] Voltage and frequency } \\
\text { control } \\
\text { [32] OBDD } \\
\text { [33] WAMS } \\
\text { [34] Complex network } \\
\text { theory }\end{array}$ & $\begin{array}{l}\text { [14] Decision-making } \\
\text { [40] Integer linear } \\
\text { programming } \\
\text { [46] Dynamic decision- } \\
\text { making }\end{array}$ & $\begin{array}{l}\text { [63] Unit start-up coordination } \\
\text { [64] Network reconfiguration } \\
\text { coordination }\end{array}$ & $\begin{array}{l}\text { [13] Multi-agent } \\
\text { [78] Single machine equivalent }\end{array}$ \\
\hline 2012 & $\begin{array}{l}\text { [8] Fuzzy sets } \\
\text { [11] Multi-agent } \\
\text { [25] Vague sets } \\
\text { [31] Protection issue }\end{array}$ & $\begin{array}{l}\text { [41] Lexicographic } \\
\text { optimization } \\
\text { [49] Data envelopment } \\
\text { analysis }\end{array}$ & [62] Maximizing restorable load & $\begin{array}{l}\text { [76] Observability analysis } \\
\text { [77] Precise determination of } \\
\text { generators loading }\end{array}$ \\
\hline 2013 & $\begin{array}{l}\text { [7] Artificial neutral } \\
\text { network } \\
\text { [20] Successful rate } \\
\text { [22] Decision-making } \\
\text { [26] Group decision- } \\
\text { making }\end{array}$ & [55] Load pickup & $\begin{array}{l}\text { [57] Recovery timing } \\
\text { [61] WAMS real-time status }\end{array}$ & \\
\hline 2014 & [36] Spectral clustering & $\begin{array}{l}\text { [39] Decision making } \\
\text { [42] Line restoration sequence }\end{array}$ & & $\begin{array}{l}\text { [65] Complex network theory } \\
\text { [66] Tools and challenges } \\
\text { [68] Spanning tree search } \\
\text { [71] Adjacent microgrid power } \\
\text { support } \\
\text { [74] VSC characteristics }\end{array}$ \\
\hline 2015 & $\begin{array}{l}\text { [9] Graph theory } \\
\text { [35] Bi-level programming }\end{array}$ & $\begin{array}{l}\text { [45] Fuzzy chance } \\
\text { programming } \\
\text { [47] Group decision-making } \\
\text { [48] Group decision-making } \\
\text { [50] Line restoration risk } \\
\text { [52] Hierarchical } \\
\text { collaborative }\end{array}$ & & $\begin{array}{l}\text { [70] Stochastic methods } \\
\text { [72] Firefly optimization } \\
\text { [73] Black start integration of wind } \\
\text { power } \\
\text { [79] Malicious hacker }\end{array}$ \\
\hline 2016 & [18] Resource allocation & & [59] Cold load pickup & $\begin{array}{l}\text { [80] Ransomware via a phishing } \\
\text { attack }\end{array}$ \\
\hline
\end{tabular}


A statistical result of reviewed publications with a simple key word for method or purpose is listed in Table 1. The most popular technologies for developing restoration plans are various forms of artificial intelligence. Cold load pickup is serious concern in load restoration without enough research yet.

\section{Conclusions}

Although a great amount of research has strengthening power system to be resilient against outages, the risk of large-scale blackouts does not disappear. This paper discusses the advances and hot topics in power system restoration in the past decade. A large amount of work has been done and great progress has been made towards fast and effective power system restoration. Modern power systems have become complex cyber-physical systems due to significant integration of variable renewable energy, rapid development of smart grid and wide application of emerging techniques. Many new factors have the ability to cause a widespread blackout. Unlike preventive, corrective and emergency control, state-of-the-art technologies for restoration have barely achieved online application. There is still a very long way to go to realize automatic self-healing in bulk power systems.

Step-by-step dynamic decision-making based on situation awareness from SCADA and WAMS will be realized in the near future with effective application of fast developing artificial intelligence technologies. Furthermore, a comprehensive understanding of the sociotechnical role in electricity outages within broader disaster contexts can only be improved through interdisciplinary research [81]. In addition, several to dozen UltraHVDC projects will transmit about $100 \mathrm{GW}$ power to the east of China. Due to the multi-infeed HVDC interaction [82], the control and management of the most complex Ultra-high voltage power system in the world will meet more new challenges. Therefore, it is extremely urgent to do much more research to achieve fast and reliable restoration when the system is facing increasing blackout risks.

Acknowledgment This work was supported by National Basic Research Program of China (973 Program) (No. 2012CB215101).

Open Access This article is distributed under the terms of the Creative Commons Attribution 4.0 International License (http:// creativecommons.org/licenses/by/4.0/), which permits unrestricted use, distribution, and reproduction in any medium, provided you give appropriate credit to the original author(s) and the source, provide a link to the Creative Commons license, and indicate if changes were made.

\section{References}

[1] Allen EH, Stuart RB, Wiedoan TE (2014) No light in August: power system restoration following the 2003 North American blackout. IEEE Power Energy Mag 12(1):24-33

[2] Xue YS, Xiao SJ (2013) Generalized congestion of power systems: insights from the massive blackouts in India. J Mod Power Syst Clean Energy 1(2):91-100. doi:10.1007/s40565-013-00142

[3] Massound A (2014) A smart self-healing grid: in pursuit of a more reliable and resilient system. IEEE Power Energy Mag 12(1):108-110+112

[4] Liu YT, Wang HT, Ye H (2014) Power system restoration theory and technology. Science and Technology Press, Beijing

[5] Zhou YH, Hu XY, Luo B (2007) Design of a case based reasoning system for power system resotration. Autom Electr Power Syst 31(18):87-90

[6] Wang HT, Liu YT (2009) Multi-objective optimization of power system reconstruction based on NSGA-II. Autom Electr Power Syst 33(23):14-18

[7] Iman S, Abbas K, Rene F (2013) The study of switching overvoltages under power system restoration scenario using extended delta-bar-delta algorithm. Int J Emerg Electr Power Syst 14(3):219-230

[8] Liu WJ, Lin ZZ, Wen FS et al (2012) Intuitionistic fuzzy Choquet integral operator-based approach for black-start decision-making. IET Gener Transm Distrib 6(5):378-386

[9] Quirós-Tortós J, Panteli M, Wall P et al (2015) Sectionalising methodology for parallel system restoration based on graph theory. IET Gener Transm Distrib 8(11):1216-1225

[10] Ye DY, Zhang MJ, Sutanto D (2011) A hybrid multiagent framework with Q-learning for power grid systems restoration. IEEE Trans Power Syst 26(4):2434-2441

[11] Ren FH, Zhang MJ, Soetanto D et al (2012) Conceptual design of a multi-agent system for interconnected power systems restoration. IEEE Trans Power Syst 27(2):732-740

[12] Wang HT, Liu YT, Qiu XZ et al (2006) Multi-agent based on stackelberg decision for power system restoration. Autom Electr Power Syst 30(15):5-9

[13] Xu YL, Liu WX (2011) Novel multiagent based load restoration algorithm for microgrids. IEEE Trans Smart Grid 2(1):152-161

[14] Hou YH, Liu CC, Sun K et al (2011) Computation of milestones for decision support during system restoration. IEEE Trans Power Syst 26(3):1399-1409

[15] Lindenmeyer D, Dommel HW, Adibi MM (2001) Power system restoration-a bibliographical survey. Int J Electr Power Energy Syst 23(3):219-227

[16] Gholami M, Moshtagh J, Ghadernejad N (2015) Service restoration in distribution networks using combination of two heuristic methods considering load shedding. J Mod Power Syst Clean Energy 3(4):556-564. doi:10.1007/s40565-015-0139-6

[17] Barsali S, Poli D, Praticò A et al (2008) Restoration islands supplied by gas turbines. Electr Power Syst Res 78(12):2004-2010

[18] Qiu F, Wang JH, Chen C et al (2016) Optimal black start resource allocation. IEEE Trans Power Syst 31(3):2493-2494

[19] Feltes JW, Grande-Moran C, Duggan P et al (2006) Some considerations in the development of restoration plans for electric utilities serving large metropolitan areas. IEEE Trans Power Syst 21(2):909-915

[20] Zhu HN, Liu YT, Qiu XZ (2013) Optimal restoration unit selection considering success rate during black start stage. Autom Electr Power Syst 37(22):28-34. doi:10.7500/ AEPS20130412009 
[21] Tsai M (2008) Development of an object-oriented service restoration expert system with load variations. IEEE Trans Power Syst 23(1):219-225

[22] Chou YT, Liu CW, Wang YJ et al (2013) Development of a black start decision supporting system for isolated power systems. IEEE Trans Power Syst 28(3):2202-2210

[23] Saraf N, McIntyre K, Dumas J et al (2009) The annual black start service selection analysis of ERCOT grid. IEEE Trans Power Syst 24(4):1867-1874

[24] Zhong HR, Gu XP (2010) Assessment of power system blackstart schemes based on fuzzy analytic hierarchy process and its sensitivity analysis. Autom Electr Power Syst 34(16):34-37

[25] Zeng SQ, Lin ZZ, Wen FS et al (2012) A new approach for power system black-start decision-making with vague set theory. Int J Electr Power Energy Syst 34(1):114-120

[26] Liu WJ, Lin ZZ, Wen FS et al (2013) Analysis and optimisation of the perferences of decision-makers in black-start group decision-making. IET Gener Transm Distrib 7(2):14-23

[27] Wang HT, Liu YT (2010) Research on the black start field test of Shandong power grid based on PDCA cycle. In: Proceedings of international conference on electrical and control engineering, Wuhan, China, 25-27 June 2010, pp 4144-4148

[28] Atsushi I, Hidemi K, Toshikazu S et al (2008) Generator voltage building-up field test for $500 \mathrm{kV}$ transformer energization for blackstart power system. IEEJ Trans Power Energy 128(4):641-646

[29] Fendin H, Hansén T, Hemmingsson M et al (2011) Black start test of the Swedish power system. In: Proceedings of IEEE Trondheim PowerTech, Trondheim, Norway, 19-23 June 2011, pp 1-5

[30] Adibi MM, Martins N (2008) Power system restoration dynamics issues. In: Proceedings of IEEE power and energy society general meeting, Pittsburgh, San Diego, USA, 20-24 July 2008, pp 1-8

[31] Apostolov A, Mysore P, Sidhu T et al (2012) An update to protection issues during system restoration. In: Proceeding of IEEE power and energy society general meeting, San Diego, USA, 22-26 July 2012, pp 1-4

[32] Wang C, Vittal V, Sun K (2011) OBDD-based sectionalizing strategies for parallel power system restoration. IEEE Trans Power Syst 26(3):1426-1433

[33] Sarmadi SAN, Dobakhshari AS, Azizi S et al (2011) A sectionalizing method in power system restoration based on WAMS. IEEE Trans Smart Grid 2(1):190-197

[34] Lin ZZ, Wen FS, Chung CY, Wong KP, Zhou H (2011) Division algorithm and interconnection strategy of restoration subsystems based on complex network theory. IET Gener Transm Distrib 5(6):674-683

[35] Liu WJ, Lin ZZ, Wen FS et al (2015) Sectionalizing strategies for minimizing outage durations of critical loads in parallel power system restoration with bi-level programming. Int J Electr Power Energy Syst 71:327-334

[36] Quirós-Tortós J, Wall P, Ding L et al (2014) Determination of sectionalising strategies for parallel power system restoration: a spectral clustering-based methodology. Electr Power Syst Res 116(1):381-390

[37] Joglekar JJ, Nerkar YP (2008) A different approach in system restoration with special consideration of islanding schemes. Int $\mathbf{J}$ Electr Power Energy Syst 30(9):519-524

[38] Liu YT, Wang CY (2009) A group intelligent decision support system for power system skeleton restoration based on data warehouse. Autom Electr Power Syst 33(1):1-6

[39] Zhang C, Lin ZZ, Wen FS et al (2014) Two-stage power network reconfiguration strategy considering node importance and restored generation capacity. IET Gener Transm Distrib $8(1): 91-103$
[40] Sun W, Liu CC, Zhang L (2011) Optimal generator start-up strategy for bulk power system restoration. IEEE Trans Power Syst 26(3):1357-1366

[41] Gu X, Zhong H (2012) Optimisation of network reconfiguration based on a two-layer unit-restarting framework for power system restoration. IET Gener Transm Distrib 6(7):693-700

[42] Zhu HN, Liu YT (2014) Multi-objective optimization of unit restoration during network reconstruction considering line restoration sequence. Autom Electr Power Syst 38(16):53-59. doi:10.7500/AEPS20131104013

[43] Liu Y, Gu XP (2007) Skeleton-network reconfiguration based on topological characteristics of scale-free networks and discrete particle swarm optimization. IEEE Trans Power Syst 22(3):1267-1274

[44] Wei ZB, Liu Y, Gu XP (2007) DPSO algorithm based network reconfiguration of power systems for maximizing load recovery efficiency. Autom Electr Power Syst 31(1):38-42

[45] Zhang XL, Liang HP, Zhu T et al (2015) Optimiazation of power network reconfiguration based on fuzzy chance constrained programming. Autom Electr Power Syst 39(14):68-74. doi:10.7500/AEPS20141029008

[46] Wang CY, Liu YT (2011) A dynamic optimiazation decisionmaking method for power system skeleton restoration. Autom Electr Power Syst 35(2):24-27

[47] Liu YT, Sun PB, Wang CY (2015) Group decision support system for backbone-network reconfiguration. Int J Electr Power Engry Syst 71:391-402

[48] Sun PB, Liu YT, Qiu XZ et al (2015) Hybrid multiple attribute group decision-making for power system restoration. Expert Syst Appl 42(19):6795-6805

[49] Shi LB, Ding HL, Zhao X (2012) Determination of weight coefficient for power system restoration. IEEE Trans Power Syst 27(2):1140-1141

[50] Sun L, Liu WJ, Lin ZZ et al (2015) Determintion of optimal restoration paths for power system considering failure risk of restoring transmission lines. Autom Electr Power Syst 39(23):75-82. doi:10.7500/AEPS20150214006

[51] Lin ZZ, Wen FS (2009) A new optimization method for determining restoration paths based on weighted complex network model. Autom Electr Power Syst 33(6):11-14

[52] Cao X, Wang HT, Liu YT (2015) A hierarchical collaborative optimization method for transmission network restoration. Proc CSEE 35(19):4906-4917

[53] Wang C, Vittal V, Kolluri VS et al (2010) PTDF-based automatic restoration path selection. IEEE Trans Power Syst 25(3):1686-1695

[54] Yuan RX, Ling JY, Zhang ZY et al (2010) A genetic algorithm method for standing phase angle reduction in power system restoration. In: Proceedings of IEEE power and energy society general meeting, Minneapolis, USA, 25-29 July 2010, pp 1-6

[55] Ye H, Liu YT (2013) A new method for standing phase angle reduction in system restoration by incorporating load pickup as a control means. Int J Electr Power Energy Syst 53(4):664-674

[56] Mota AA, Mota MTM, Morelato A (2007) Visualization of power system restoration plans using CPM/PERT graphs. IEEE Trans Power Syst 22(3):1322-1329

[57] Duffey RB, Ha T (2013) The probability and timing of power system restoration. IEEE Trans Power Syst 28(1):3-9

[58] Kumar V, Gupta I, Gupta HO (2006) An overview of cold load pickup issues in distribution systems. Electr Power Compon Syst 34(6):639-651

[59] Medina DR, Rappold E, Sanchez O (2016) Fast assessment of frequency response of cold load pickup in power system restoration. IEEE Trans Power Syst 31(4):3249-3256 
[60] Cheng GH, Xu Z (2007) Optimal load restoration based on particle swarm optimization. Autom Electr Power Syst 31(16):62-65

[61] Liu WJ, Lin ZZ, Wen FS et al (2013) A wide area monitoring system based load restoration method. IEEE Trans Power Syst 28(2):2025-2034

[62] Qu HB, Liu YT (2012) Maximizing restorable load amount for specific substation during system restoration. Int J Electr Power Energy Syst 43(1):1213-1220

[63] Qu HB, Liu YT (2011) Load restoration optimization during unit start-up stage. Autom Electr Power Syst 35(8):16-21

[64] Qu HB, Liu YT (2011) Load restoration optimization during last stage of network reconfiguration. Autom Electr Power Syst 35(19):43-48

[65] Sun Y, Tang X (2014) Cascading failure analysis of power flow on wind power based on complex network theory. J Mod Power Syst Clean Energy 2(4):411-421. doi:10.1007/s40565-0140088-5

[66] Liu SS, Hou YH, Liu CC et al (2014) The healing touch: tools and challenges for smart grid restoration. IEEE Power Energy Mag 12(1):54-63

[67] Pham TTH, Bésanger Y, Hadjsaid N (2009) New challenges in power system restoration with large scale of dispersed generation insertion. IEEE Trans Power Syst 24(1):398-406

[68] Li J, Ma XY, Liu CC et al (2014) Distribution system restoration with microgrids using spanning tree search. IEEE Trans Power Syst 29(6):3021-3029

[69] Moreira CL, Resende FO, Lopes JAP (2007) Using low voltage microgrids for service restoration. IEEE Trans Power Syst 22(1):395-403

[70] Zhao BY, Dong XD, Bornemann J (2015) Service restoration for a renewable-powered microgrid in unscheduled island mode. IEEE Trans Smart Grid 6(3):1128-1136

[71] Che L, Khodayar M, Shahidehpour M (2014) Only connect: microgrids for distribution system restoration. IEEE Power Energy Mag 12(1):70-81

[72] Ei-Zonkoly A (2015) Integration of wind power for optimal power system black-start restoration. Turk J Electr Eng Comput Sci 23(6): 1853-1866

[73] Teng W, Wang HT, Jia YZ (2015) Construction and control strategy research of black start unit containing wind farm. In: Proceedings of IEEE region 10 conference (TENCON), Macau, China, 1-4 November 2015, pp 1-5

[74] Bahrman M, Bjorklund PE (2014) The new black start: system restoration with help from voltage-sourced converters. IEEE Power Energy Mag 12(1):44-53

[75] Barsali S, Salvati R, Zaottini R (2009) Use of HVDC links for power system restoration. Electr Power Syst Res 79(6):973-983
[76] Nourizadeh S, Sarmadi SAN, Karimi MJ et al (2012) Power system restoration planning based on wide area measurement system. Int J Electr Power Energy Syst 43(1):526-530

[77] Nourizadeh S, Karimi MJ, Ranjbar AM (2012) Power system stability assessment during restoration based on a wide area measurement system. IET Gener Transm Distrib 6(11):1171-1179

[78] Nourizadeh S, Yari V, Ranjbar AM (2011) Frequency monitoring and control during power system restoration based on wide area measurement system. Math Prob Eng 21(1):1-13

[79] Ukraine blackout is a cyberattack milestone. http://www.cnet. com/news/cyberattack-causes-widespread-power-blackout-inukraine/

[80] New analysis: no, Israel's power grid wasn't hacked, but ransom ware hit Israel's Electric Authority. Computer world January 27 2016. http://www.computerworld.com/article/3026609/security/ no-israels-power-grid-wasnt-hacked-but-ransomware-hitisraels-electric-authority.html

[81] Miles SB, Jagielo N, Gallagher H (2016) Hurricane Isaac power outage impacts and restoration. J Infrastruct Syst. doi:10.1061/ (ASCE)IS.1943-555X.0000267

[82] Yang D, Zhao K, Liu Y (2014) Coordinated optimization for controlling short circuit current and multi-infeed DC interaction. J Mod Power Syst Clean Energy 2(4):374-384. doi:10.1007/ s40565-014-0081-z

Yutian LIU received the Ph.D. degree from Xi' an Jiaotong University, China, in 1994. He is the Taishan Chair Professor of School of Electrical Engineering, Shandong University, China. His research interests include power system stability and restoration, smart grid and renewable energy sources integration.

Rui FAN received the B.E. degree in electrical engineering from Hunan University, China, in 2014. He is currently pursuing the Ph.D. degree in the School of Electrical Engineering, Shandong University. His main research interest is power system restoration.

Vladimir TERZIJA is the EPSRC Chair Professor in power system engineering in the School of Electrical and Electronic Engineering, The University of Manchester, U.K. He is the Oversea Taishan Scholar of School of Electrical Engineering, Shandong University, China. His main research interests are smart grid, application of intelligent methods to power system monitoring, control, and protection, switchgear and fast transient processes. 